\title{
Analysis of correlation between viscosity Arrhenius parameters: Extension to ternary liquid mixtures
}

\author{
R.H. Kacem ${ }^{1, *}$, Mohamed Dallel ${ }^{2}$, Nuhed Al-Omair ${ }^{3}$, Ahlam Al-Arfaj ${ }^{3}$, Nora Alzamel ${ }^{3}$ and \\ Noureddine Ouerfelli ${ }^{2,3}$ \\ ${ }^{1}$ Department of Quantitative Methods, FSEGN, University of Carthage, Tunisia \\ ${ }^{2}$ Institut Supérieur des Technologies Médicales de Tunis, LR13SE07, University of Tunis El Manar, Tunisia \\ ${ }^{3}$ Department of Chemistry, College of science, Imam Abdulrahman Bin Faisal University, KSA
}

\begin{abstract}
The study of viscosity-temperature dependence is important for the design and the optimization of several industrial processes and products. In this context, an interesting equation is recently proposed for pure solvents correlating the two parameters of the viscosity Arrhenius-type equation, as knowing the activation energy $(E a)$ and the pre-exponential factor $(A s)$, allowing the simplification of the viscosity Arrhenius equation to become an expression depending on only one parameter instead of two. The present work investigates the validity of the simplified Arrhenius-type equation for ternary fluids mixtures. The extension of the proposed equation to ternary liquid mixtures is very important since it simplifies the estimation of viscous behavior and the ensuing calculations. Using statistical methods and 114 experimental data from the literature on viscosity for 5 ternary liquid mixtures over different temperature ranges at atmospheric pressure, we found that the validation of the proposed equation depends significantly on the density of liquids and is validated only for 4 studied ternary liquid mixtures. This result opens the way to investigate the sensitivity of the equation's parameters for more specific mixtures.
\end{abstract}

Keywords: Viscosity; ternary mixture; Arrhenius temperature; correlation; statistics

\section{Introduction}

Fluids viscosity is one of the main transport property involved in chemical engineering and several industries such as food industry, cosmetics and pharmaceuticals, etc. Indeed, viscosity is essential for hydraulic calculations of fluid transport and for energy transference computation ${ }^{1-6}$. Consequently, several theoretical, semi-theoretical and empirical equations of fluid viscosity have been proposed in the literature following three main theories: the reaction rate theory of Eyring ${ }^{7-9}$, the molecular dynamic approach proposed by Cumming and Evans ${ }^{10}$ and the distribution function theory of Kirkwood et al. ${ }^{11}$.

Particularly, several studies have been made in order to analyze the viscosity-temperature dependence. Thus, different expressions have been suggested in the literature for modeling the liquid viscosity $(\eta)$ against temperature $(T)$ through available experimental data for an interpolation aim ${ }^{12-24}$.

In this context, Kacem et al. ${ }^{25}$ have recently found a significant correlation between the two parameters of viscosity Arrhenius-type equation for some common solvents, which are the Arrhenius energy $(E a)$ and the factor ( $\ln \mathrm{As})$. Hence, they have proposed an empirical equation modeling this

*Corresponding author: Rami Haj Kacem

Email address: rami.bhk@isffs.rnu.tn

DOI: http://dx.doi.org/10.13171/mjc65/0171114633rhk relationship and then they have proposed a simplified expression of the Arrhenius-type equation.

The current work aims to extend the validity of the Kacem et al. ${ }^{25}$ models to ternary mixtures. For that, statistical tools are applied using data sets from the literature of ternary liquid mixtures at different compositions and temperature ranges ${ }^{26,27}$.

The validation of the proposed equation is important since it allows redefining the Arrhenius equation by using single parameter instead of two. The advantages and benefits of such scheme are obvious to the computational aspects in a myriad of disciplines in engineering and science.

\section{The temperature dependence of liquid} viscosity: a literature review

Several equations have been proposed in the literature for representing the liquid viscosity $(\eta)$ upon temperature $(T)$ through experimental data for interpolation purpose. Generally, they differ according to the number of parameters. For that, one can classify them into three categories: two-constant, three-constant and multi-constants equation.

The representation of Newtonian liquid viscositytemperature dependence with two parameters is proposed initially by Guzman ${ }^{12}$ and known as the

Received September 29, 2017

Accepted, October 25, 2017

Published November 14, 2017 
Andrade equation as following:

$\eta=A e^{\frac{B}{T}}$

where $A$ and $B$ are positive constants and are characteristics of each pure liquid.

Following the Andrade equation, many expressions have been suggested based on two parameters ${ }^{13-15}$. However, the most popular is the Arrhenius typeequation which may be expressed as following:

$\ln \eta=\ln A_{s}+\frac{E_{a}}{R}\left(\frac{1}{T}\right)$

Where $R, E_{\mathrm{a}}$ and $A_{\mathrm{s}}$ are the perfect gas constant, the Arrhenius activation energy and the preexponential factor of the Arrhenius equation.

Also, considering the Newtonian liquids not obeying to the Arrhenius behavior, several non-linear models with two parameters are proposed which are ranging from semi-theoretical to purely empirical and discussed in previous works ${ }^{14-24}$.

The three-constant representation of the viscosity-temperature dependence is proposed originally by Vogel ${ }^{17}$ and known as Vogel-FulcherTammann-type equation ${ }^{17,19}$ :

$\ln \eta=A-\frac{B}{T-C}$

Where $A, B$ and $C$ are constants.

Following Vogel, several researchers have proposed similar expressions of the viscosity-temperature dependence ${ }^{14,15,20}$. In addition, others researcher have proposed different forms using three parameters such as the Eq. 5 and Eq. 6, which are proposed by Girifalco ${ }^{20}$ and Thorpe and Rodger ${ }^{21}$ respectively.

$\eta=\frac{C}{1+A T+B T^{2}}$

$\ln \eta=A+\frac{B}{T}+\frac{D}{T^{2}}$

where $A, B$ and $C$ are parameters' models.

Concerning the expressions based on more than three constants, they have been proposed in the aim to improve the accuracy of the representation, particularly over wider ranges of temperature. The most popular multi-constant equations are polynomials, such as the Eq. $7^{16}$ with 4 parameters and the Eq. $8^{24}$ with 5 parameters.

$\ln \eta=A+\frac{B}{T}+C . T+D T^{2}$

$\ln \eta=A+\frac{B}{T}+C \cdot \ln T+D T^{E}$

where $A, B, C D$ and $E$ are the equation' parameters.
Recently, Kacem et al. ${ }^{25}$ have shown a significant correlation between the two parameters of viscosity Arrhenius-type equation, the Arrhenius activation energy $(E a)$ and the pre-exponential factor $(\ln A s)$ for some pure solvents studied at different temperature ranges. Thus, they have proposed the following equations linking the two parameters:

$E_{a}=R \times\left(-\ln A_{s}\right)^{2.933}$
$\ln A_{s}=-\left(\frac{E_{a}}{R}\right)^{0.341}$

where $R$ is the gas constant.

Hence, according to Kacem et al. ${ }^{25}$, the Arrhenius-type equation can be simplified to become an expression based on only one parameter instead of two ones as following:

$$
\begin{aligned}
& \ln \eta=\ln A_{s}+\lambda\left(-\ln A_{s}\right)^{2.933}\left(\frac{1}{T}\right) \\
& \ln \eta=-\left(\frac{E_{a}}{R}\right)^{0.341}+\frac{E_{a}}{R} \cdot\left(\frac{1}{T}\right)
\end{aligned}
$$

Note that the Kacem et al. ${ }^{25}$ expressions have been also validated for binary mixtures and some specific families of liquids such as alcohols, organic acids, aldehydes, ketones, alkanes, etc ${ }^{28-31}$.

\section{Empirical investigation: extension to ternary mixtures}

Assuming the validation of the Kacem-Ouerfelli equations, Eq. (9) to Eq. (12), for pure and binary liquids mixture, our investigation will focus on analyzing its eventual extended validity to ternary fluid mixtures. For that, we use 114 experimental data from the literature on viscosity for 5 ternary liquid mixtures over different temperature ranges at atmospheric pressure 26, 27. Thus, the proposed investigation will be based on analyzing the predictive power of Kacem-Ouerfelli equations by comparing the experimental with the estimated values of the Arrhenius-type equation parameters, as knowing the Arrhenius activation energy $E a\left(\mathrm{~kJ} \cdot \mathrm{mol}^{-1}\right)$ and the logarithm of the entropic factor of Arrhenius $\ln (A s / \mathrm{Pa} \cdot \mathrm{s})$.

Table 1 presents the experimental values of Arrhenius activation energy $E a\left(\mathrm{~kJ} \cdot \mathrm{mol}^{-1}\right)$ and the logarithm of the entropic factor of Arrhenius $\ln (A s / \mathrm{Pa} \cdot \mathrm{s})$. In addition, for the discussion, we report in the same Table other temperature parameters as defined by Kacem et al. ${ }^{25}$, as knowing the Arrhenius temperature $\left(T_{A} / \mathrm{K}\right)$ and the Arrhenius activation temperature $\left(T^{*} / \mathrm{K}, \mathrm{T}^{*}=\mathrm{Ea} / \mathrm{R}\right)^{25,28-30}$. 
Table 1. Experimental values of Arrhenius activation energy Ea ( $\mathrm{kJ} \cdot \mathrm{mol}-1)$, the logarithm of the entropic factor of Arrhenius $\ln (\mathrm{As} / \mathrm{Pa} \cdot \mathrm{s})$, the Arrhenius temperature TA $(\mathrm{K})$ and the Arrhenius activation temperature $\left(\mathrm{T}^{*}=\mathrm{Ea} / \mathrm{R} / \mathrm{K}\right)$ for 5 ternary liquid mixtures.

\begin{tabular}{|c|c|c|c|c|}
\hline System & $T * / \mathrm{K}$ & $\ln A s$ & $E \boldsymbol{a}$ & $T A / \mathbf{K}$ \\
\hline \multirow[b]{2}{*}{ Mixture (1) ${ }^{26}$} & 1824 & -12.3342 & 15.1656 & 147.8811 \\
\hline & 1806.422 & -12.2191 & 15.01944 & 147.8364 \\
\hline \multirow{9}{*}{$\begin{array}{l}\text { Water (1) + ethane-1,2-diol } \\
(2)+\text { methanol (3) }\end{array}$} & 1939.484 & -12.5787 & 16.12579 & 154.1879 \\
\hline & 1904.363 & -12.4472 & 15.83377 & 152.9951 \\
\hline & 1968.904 & -12.7341 & 16.3704 & 154.6172 \\
\hline & 1957.391 & -12.7695 & 16.27468 & 153.2869 \\
\hline & 1861.824 & -12.5763 & 15.48009 & 148.0427 \\
\hline & 1782.675 & -12.4339 & 14.822 & 143.3727 \\
\hline & 1593.071 & -11.9574 & 13.24555 & 133.229 \\
\hline & 1407.004 & -11.534 & 11.69849 & 121.9874 \\
\hline & 1904.53 & -13.4136 & 15.83516 & 141.9849 \\
\hline \multirow[t]{2}{*}{ Mixture (2) ${ }^{26}$} & 2447.966 & -13.8519 & 20.35354 & 176.7241 \\
\hline & 2179.243 & -13.0848 & 18.11926 & 166.5482 \\
\hline \multirow{9}{*}{$\begin{array}{l}\text { Water (1) + ethane-1,2-diol } \\
\quad(2)+\text { ethanol (3) }\end{array}$} & 2199.871 & -13.1935 & 18.29077 & 166.739 \\
\hline & 2167.775 & -13.1521 & 18.0239 & 164.823 \\
\hline & 2146.622 & -13.2296 & 17.84803 & 162.2587 \\
\hline & 2084.679 & -13.157 & 17.33301 & 158.4463 \\
\hline & 2060.626 & -13.2316 & 17.13302 & 155.7355 \\
\hline & 2045.117 & -13.297 & 17.00407 & 153.803 \\
\hline & 1928.62 & -13.0536 & 16.03545 & 147.746 \\
\hline & 1524.964 & -11.9195 & 12.67927 & 127.9384 \\
\hline & 1904.53 & -13.4136 & 15.83516 & 141.9849 \\
\hline \multirow[t]{2}{*}{ Mixture (3) ${ }^{26}$} & 2800.711 & -14.6971 & 23.28643 & 190.5616 \\
\hline & 2547.764 & -14.0756 & 21.18332 & 181.0064 \\
\hline \multirow{9}{*}{$\begin{array}{l}\text { Water (1) + ethane-1,2-diol } \\
\text { (2) + propanol (3) }\end{array}$} & 2473.307 & -13.9532 & 20.56424 & 177.2571 \\
\hline & 2389.758 & -13.7991 & 19.86957 & 173.1819 \\
\hline & 2284.342 & -13.634 & 18.9931 & 167.548 \\
\hline & 2101.063 & -13.2064 & 17.46923 & 159.0939 \\
\hline & 1899.338 & -12.6844 & 15.792 & 149.7385 \\
\hline & 1792.776 & -12.4537 & 14.90598 & 143.955 \\
\hline & 1767.944 & -12.5135 & 14.69952 & 141.2826 \\
\hline & 1442.438 & -11.6444 & 11.99311 & 123.8738 \\
\hline & 1904.53 & -13.4136 & 15.83516 & 141.9849 \\
\hline \multirow{24}{*}{$\begin{array}{c}\text { Mixture (4) } \\
\text { dimethyl carbonate (1) + } \\
\text { methanol (2) + ethanol (3) }\end{array}$} & 1646.216 & -12.5991 & 13.68742 & 130.6618 \\
\hline & 1570.879 & -12.479 & 13.06103 & 125.8817 \\
\hline & 1367.654 & -11.911 & 11.37132 & 114.823 \\
\hline & 1355.522 & -11.9292 & 11.27045 & 113.6304 \\
\hline & 1246.313 & -11.634 & 10.36243 & 107.127 \\
\hline & 1188.008 & -11.4738 & 9.877658 & 103.5411 \\
\hline & 1166.654 & -11.4151 & 9.700114 & 102.203 \\
\hline & 1115.481 & -11.2522 & 9.274638 & 99.13448 \\
\hline & 1489.684 & -12.1325 & 12.38593 & 122.7849 \\
\hline & 1404.552 & -11.9836 & 11.67811 & 117.2067 \\
\hline & 1357.874 & -11.8994 & 11.29001 & 114.1132 \\
\hline & 1280.355 & -11.7252 & 10.64547 & 109.1968 \\
\hline & 1204.133 & -11.5213 & 10.01173 & 104.5136 \\
\hline & 1180.536 & -11.4865 & 9.815533 & 102.7756 \\
\hline & 1300.91 & -11.8687 & 10.81638 & 109.6088 \\
\hline & 1390.66 & -11.855 & 11.5626 & 117.3059 \\
\hline & 1366.565 & -11.9022 & 11.36227 & 114.8162 \\
\hline & 1260.941 & -11.6415 & 10.48406 & 108.3146 \\
\hline & 1003.808 & -10.8072 & 8.346136 & 92.88361 \\
\hline & 1194.154 & -11.524 & 9.928762 & 103.6229 \\
\hline & 1197.942 & -11.5482 & 9.960252 & 103.7338 \\
\hline & 1339.557 & -11.7179 & 11.13771 & 114.3177 \\
\hline & 1327.974 & -11.8139 & 11.0414 & 112.4075 \\
\hline & 1265.691 & -11.7006 & 10.52355 & 108.173 \\
\hline
\end{tabular}




\begin{tabular}{|c|c|c|c|c|}
\hline & 1220.328 & -11.61 & 10.14639 & 105.1098 \\
\hline & 1003.392 & -10.9026 & 8.342677 & 92.03278 \\
\hline & 1354.878 & -11.8547 & 11.26509 & 114.2904 \\
\hline & 1299.743 & -11.7822 & 10.80668 & 110.3146 \\
\hline & 1234.66 & -11.6424 & 10.26555 & 106.0487 \\
\hline & 1203.135 & -11.5866 & 10.00343 & 103.8383 \\
\hline & 1327.512 & -11.8257 & 11.03756 & 112.2569 \\
\hline & 1268.538 & -11.7302 & 10.54723 & 108.1432 \\
\hline & 1211.472 & -11.6118 & 10.07275 & 104.3308 \\
\hline & 1292.427 & -11.7689 & 10.74584 & 109.8176 \\
\hline & 1223.924 & -11.6355 & 10.17629 & 105.1886 \\
\hline & 1247.644 & -11.6822 & 10.3735 & 106.7985 \\
\hline & 1255.61 & -11.7229 & 10.43973 & 107.1072 \\
\hline & 1342.972 & -11.8601 & 11.16611 & 113.2348 \\
\hline & 1602.861 & -12.3284 & 13.32695 & 130.0138 \\
\hline & 1150.258 & -11.4459 & 9.563791 & 100.4957 \\
\hline Mixture (5) 27 & 946.8005 & -11.2866 & 7.872147 & 83.88703 \\
\hline & 921.1461 & -11.1775 & 7.658844 & 82.41067 \\
\hline dimethyl carbonate $(1)+$ & 965.0956 & -11.2737 & 8.024261 & 85.60606 \\
\hline methanol (2) + hexane (3) & 985.7952 & -11.2868 & 8.196367 & 87.34039 \\
\hline & 1020.092 & -11.3256 & 8.481524 & 90.06992 \\
\hline & 1084.317 & -11.4563 & 9.015525 & 94.64827 \\
\hline & 1034.725 & -11.2098 & 8.603191 & 92.30546 \\
\hline & 1029.805 & -11.0807 & 8.562288 & 92.93659 \\
\hline & 970.7292 & -11.3392 & 8.071101 & 85.60866 \\
\hline & 1013.702 & -11.4408 & 8.4284 & 88.60445 \\
\hline & 1022.184 & -11.417 & 8.498919 & 89.53178 \\
\hline & 1046.111 & -11.4357 & 8.697863 & 91.47765 \\
\hline & 1027.826 & -11.3023 & 8.545834 & 90.94002 \\
\hline & 1070.86 & -11.3428 & 8.903633 & 94.40882 \\
\hline & 1106.645 & -11.3658 & 9.201165 & 97.3658 \\
\hline & 1055.238 & -11.5579 & 8.773745 & 91.30037 \\
\hline & 1061.242 & -11.5339 & 8.823666 & 92.0107 \\
\hline & 1071.722 & -11.5209 & 8.9108 & 93.02378 \\
\hline & 998.9962 & -11.1949 & 8.306127 & 89.23671 \\
\hline & 995.8475 & -11.0891 & 8.279946 & 89.80396 \\
\hline & 1277.691 & -11.9522 & 10.62332 & 106.9002 \\
\hline & 1101.956 & -11.6399 & 9.16218 & 94.67093 \\
\hline & 1129.784 & -11.7028 & 9.393554 & 96.53932 \\
\hline & 1169.733 & -11.7658 & 9.725712 & 99.41811 \\
\hline & 1175.381 & -11.729 & 9.772675 & 100.2113 \\
\hline & 1085.669 & -11.333 & 9.026769 & 95.79688 \\
\hline & 1279.252 & -12.1527 & 10.6363 & 105.2652 \\
\hline & 1151.009 & -11.7043 & 9.570029 & 98.34057 \\
\hline & 1103.259 & -11.4889 & 9.173013 & 96.02796 \\
\hline & 1309.139 & -12.0749 & 10.8848 & 108.4187 \\
\hline & 1205.508 & -11.8394 & 10.02316 & 101.8221 \\
\hline & 1190.300 & -11.7697 & 9.89672 & 120.2722 \\
\hline & 1151.669 & -11.5634 & 9.575518 & 99.5965 \\
\hline & 1189.178 & -11.7295 & 9.887384 & 101.3839 \\
\hline & 1189.16 & -11.673 & 9.887234 & 101.8723 \\
\hline & 1204.732 & -11.699 & 10.01671 & 102.9778 \\
\hline & 1166.805 & -11.5007 & 9.701364 & 101.455 \\
\hline & 1119.444 & -11.4538 & 9.307588 & 97.73569 \\
\hline & 1059.175 & -11.5361 & 8.806479 & 91.8142 \\
\hline & 905.337 & -11.1625 & 7.527399 & 81.10553 \\
\hline
\end{tabular}

Using the Eq. (9) and Eq. (10), we have estimated the experimental activation energy $(E a)_{\text {est }}$ by replacing the experimental entropic factor $(\ln A s)_{\exp }$ in Eq. (9). Also, we have estimated the entropic factor $(\ln A s)_{\text {est }}$ by replacing the experimental activation energy $(E a)_{\exp }$ of ternary liquid mixtures data in Eq. (10). Note that the precedent experimental parameters values $(\ln A s)_{\exp }$ and $(E a)_{\exp }$ are determined 
graphically and linear regression, supposing the Arrhenius behavior expressed by Eq. $2^{25,28-30}$.

Nevertheless, regarding the five ternary mixtures used in this paper, we note that the fifth mixture, dimethyl carbonate (1), methanol (2) and hexane (3), is a fluid with very low viscosity values. Consequently, in order to take into consideration any eventual effect of such mixture on results ${ }^{30}$, our analysis will be made for three different cases separately i.e., using all data, using the first four mixtures of the Table 1, defined as the Group 1 of data, and using the fifth mixture of the Table 1 (dimethyl carbonate (1), methanol (2) and hexane (3)), defined as the Group 2 of data.

Table 2 presents descriptive statistics on experimental and estimated values of parameters for each case i.e, using all data and by groups. The descriptive statistics show that the experimental data are almost similar to the corresponding $E a$-values and $\ln A s^{-}$-values estimated from Eq. (9) and Eq. (10), particularly for the Group 1. This allows as expecting a good approximation accuracy of the Kacem-Ouerfelli equations for ternary liquids mixture.

Table 2. Descriptive statistics on experimental and estimated values of $E_{a}$ and $\ln A s$.

\begin{tabular}{|c|c|c|c|c|c|c|}
\hline Sample & Size & Parameters & Mean & $\sigma$ & Min & $\operatorname{Max}$ \\
\hline \multirow[t]{4}{*}{ All data } & \multirow{4}{*}{113} & $\left(E_{a}\right)_{\exp }$ & 11.85 & 3.55 & 7.53 & 23.28 \\
\hline & & $\left(E_{a}\right)_{\mathrm{est}}$ & 12.32 & 2.49 & 8.95 & 22.05 \\
\hline & & $(\ln A s)_{\exp }$ & -12.01 & 0.78 & -14.70 & -10.81 \\
\hline & & $(\ln A s)_{\mathrm{est}}$ & -11.79 & 1.13 & -14.98 & -10.19 \\
\hline \multirow{4}{*}{$\begin{array}{c}\text { Group } 1 \\
\text { (4 mixtures) }\end{array}$} & \multirow[t]{4}{*}{73} & $\left(E_{a}\right)_{\exp }$ & 13.38 & 3.54 & 8.34 & 23.29 \\
\hline & & $\left(E_{a}\right)_{\mathrm{est}}$ & 13.18 & 2.70 & 8.95 & 22.05 \\
\hline & & $(\ln A s)_{\exp }$ & -12.28 & 0.82 & -14.70 & -10.81 \\
\hline & & $(\ln A s)_{\mathrm{est}}$ & -12.31 & 1.08 & -14.98 & -10.56 \\
\hline \multirow{4}{*}{$\begin{array}{c}\text { Group } 2 \\
\text { (Fifth mixture) }\end{array}$} & \multirow[t]{4}{*}{40} & $\left(E_{a}\right)_{\exp }$ & 9.06 & 0.82 & 7.53 & 10.89 \\
\hline & & $\left(E_{a}\right)_{\mathrm{est}}$ & 10.76 & 0.71 & 9.63 & 12.62 \\
\hline & & $(\ln A s)_{\exp }$ & -11.50 & 0.26 & -12.15 & -11.08 \\
\hline & & $(\ln A s)_{\mathrm{est}}$ & -10.85 & 0.33 & -11.56 & -10.19 \\
\hline
\end{tabular}

Also, Table 3 presents the Average Absolute Deviations (AAD) for each case, which is a good indicator of quality of approximation ${ }^{32}$. The AAD confirms that the best quality of approximation in mean is clearly in the Group 1 of mixtures where their values is very low for both parameters indicating the little discrepancy between the experimental and the estimated values.

Table 3. The Average Absolute Deviations (AAD \%)

\begin{tabular}{|c|c|c|c|}
\hline Sample & \multicolumn{2}{|c|}{ Size } & \multicolumn{2}{|c|}{ Parameters } \\
\hline All data & 113 & 11.66 & $\ln A s$ \\
\hline $\begin{array}{c}\text { Group 1 } \\
\text { (4 mixtures) }\end{array}$ & 73 & 7.60 & 3.71 \\
\hline $\begin{array}{c}\text { Group 2 } \\
\text { (Fifth mixture) }\end{array}$ & 40 & & 2.62 \\
\hline
\end{tabular}

Table 4. Result of the Wilcoxon Signed-Rank test for both parameters.

\begin{tabular}{|c|c|c|c|c|}
\hline Sample & Size & Variables & $z$ & Prob> $|z|$ \\
\hline \multirow[t]{2}{*}{ All data } & \multirow[t]{2}{*}{113} & $\left(E_{a}\right)_{\exp } \quad$ versus $\left(E_{a}\right)_{\text {est }}$ & -3.24 & 0.001 \\
\hline & & $(\ln A s)_{\mathrm{exp}}$ versus $(\ln A s)_{\mathrm{est}}$ & -4.24 & 0.000 \\
\hline \multirow{2}{*}{$\begin{array}{c}\text { Group } 1 \\
\text { (4 mixtures) }\end{array}$} & \multirow[t]{2}{*}{73} & $\left(E_{a}\right)_{\exp }$ versus $\left(E_{a}\right)_{\text {est }}$ & 1.48 & 0.14 \\
\hline & & $(\ln A s)_{\exp }$ versus $(\ln A s)_{\mathrm{est}}$ & 1.19 & 0.23 \\
\hline \multirow{2}{*}{$\begin{array}{c}\text { Group } 2 \\
\text { (Fifth mixture) }\end{array}$} & \multirow[t]{2}{*}{40} & $\left(E_{a}\right)_{\exp }$ versus $\left(E_{a}\right)_{\text {est }}$ & -5.51 & 0.00 \\
\hline & & $(\ln A s)_{\exp }$ versus $(\ln A s)_{\text {est }}$ & -5.51 & 0.00 \\
\hline
\end{tabular}


Nevertheless, descriptive statistics are useful but cannot give strong conclusions about the comparison between experimental versus estimated values. For that, there is a need to run a statistical test of comparison of populations such as the Wilcoxon Signed-Rank test ${ }^{33}$, where the null hypothesis assumes that the two samples are from populations with the same distribution and thus we can decide whether the corresponding data population distributions are statistically identical. Table 4 presents the result of the test for each used sample.

Results of the test confirm the importance of taking into consideration the density of ternary liquid mixtures. Indeed, the Wilcoxon Signed-Rank test leads to reject the null hypothesis for both parameters $E_{a}$ and $\ln A s$ if all data are used. Also, the null hypothesis is rejected for the group 2, i.e. the mixture of dimethyl carbonate (1), methanol (2) and hexane (3). However, using only the data of Group 1, the null hypothesis becomes accepted indicating that the distributions of the experimental and the estimated values are significantly the same. We deduce from

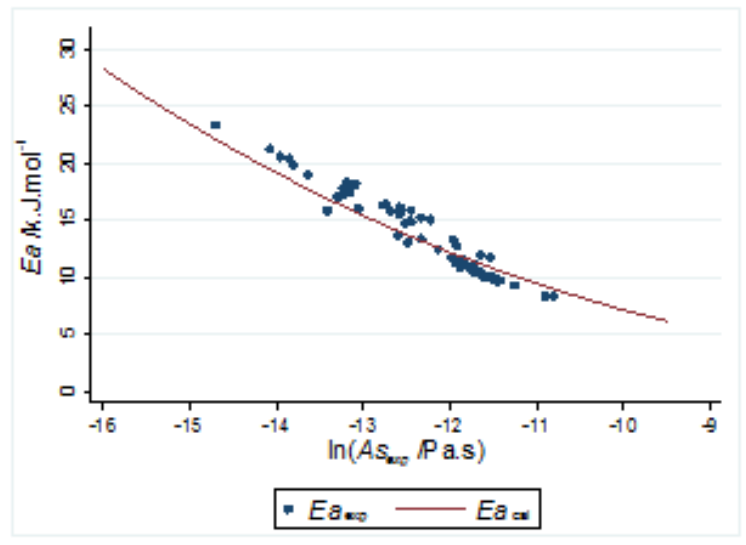

Figure 1. Comparison between the experimental and the estimated values of $E a$ as function of the experimental values $(\ln A s)_{\text {exp }}$.

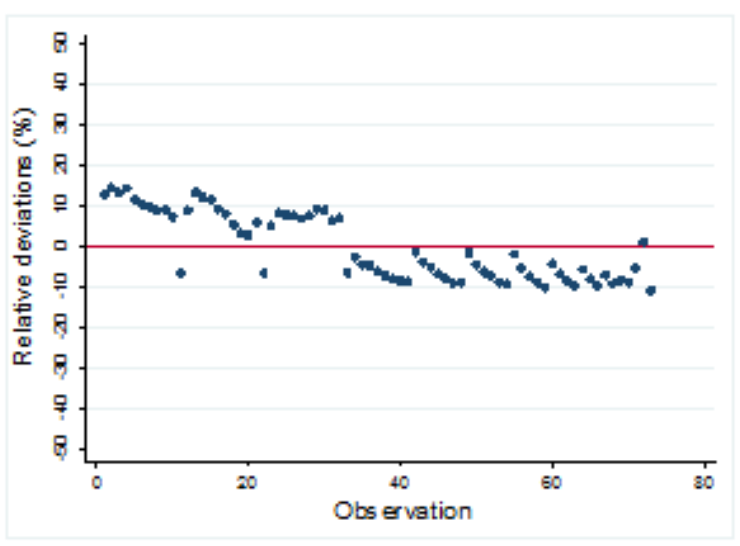

Figure 3 The relative deviations in percentage between experimental and calculated values of $E a$. that the validity of the Kacem-Ouerfelli equations for ternary mixture in addition to pure and binary liquid mixtures only for the Group 1.

In order to show the quality of approximation of the Kacem-Ouerfelli equation graphically for ternary mixture of Group 1, we present in Fig. 1 and Fig. 2 the experimental and the estimated values simultaneously for both parameters. Fig. 1 shows the experimental data of one parameter on $x$-axis with experimental and estimated values simultaneously of the second parameter on the $y$-axis. Fig. 2 shows the experimental values of the activation energy $\left(E_{a}\right)_{\text {exp }}$ and the entropic factor $(\ln A s)_{\exp }$ in direct comparison with the estimated values $\left(E_{a}\right)_{\exp }$ and $(\ln A s)_{\text {calc }}$, respectively. Thus, regarding these figures, it is clear that the gap between experimental and estimated values is indicating a slight discrepancy and confirms the good quality of approximation of the KacemOuerfelli equations and its validation for ternary liquid mixtures in addition to pure and binary liquid mixtures for the Group 1 of liquids mixtures.

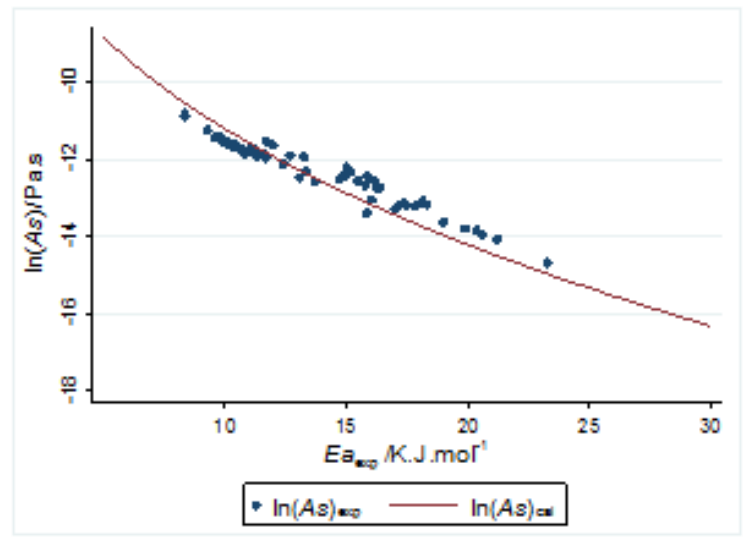

Figure 2. Comparison between the experimental and the estimated values of $\ln A s$ as function of the experimental values $(E a)_{\text {exp }}$.

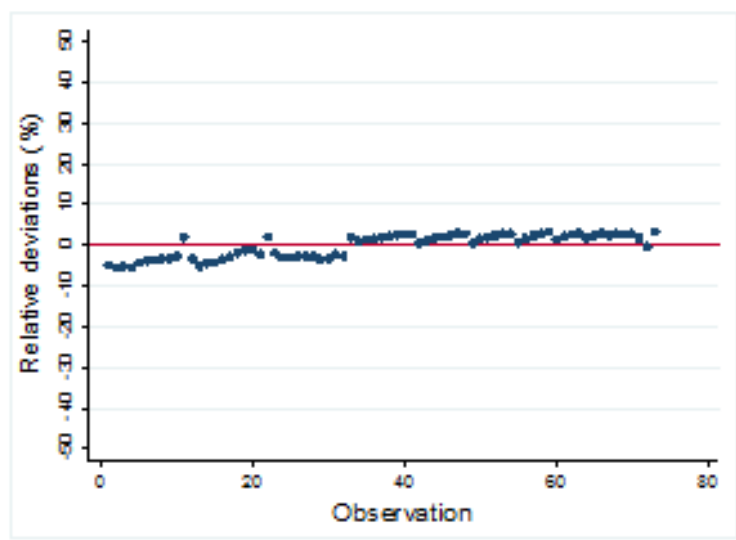

Figure 4 The relative deviations in percentage between experimental and calculated values of $\ln A s$. 
In addition, Fig. 3a and Fig. 3b illustrate the relative deviations in percentage between experimental and calculated values of both parameters for the first group of liquid mixtures. The figures

\section{Conclusion}

Assuming the validity of the equations proposed by Kacem et al. ${ }^{25}$ for pure liquids, equations (9) and (10), which model the relationship between the viscosity Arrhenius-type equation parameters, as knowing the entropic factor $(\ln A s)$ and the activation energy $(E a)$, this paper aimed to investigate their validity for ternary liquid mixtures. For that, we used a sample of 114 experimental data from the literature on viscosity for 5 ternary liquid mixtures over different temperature ranges at atmospheric pressure to estimate $\ln A s$ and $E a$.

In addition, in order to take into consideration, the low viscosity values of the fifth ternary liquid mixture (dimethyl carbonate (1), methanol (2) and hexane (3)), our analysis is made for three different cases i.e., using all data, using the first four mixtures (Group 1 of data), and using the fifth mixture, defined as the Group 2 of data.

At first, a comparison between the experiential values of the parameters $E a$ and $\ln A s$ and their estimated values using Eq. (9) and Eq. (10) is made based on descriptive statistics and the Average Absolute Deviations (AAD). Results show that the experimental data are almost similar to the corresponding estimated values only for the first Group of ternary liquid mixture.

In addition, results of the Wilcoxon Signed-Rank test leads to accept the null hypothesis only for the first group of data indicating that the distributions of the experimental and the estimated values are significantly the same. Different graphical methods are also used; all showed clearly that the gap between experimental and estimated values is indicating a slight discrepancy for the first group of ternary mixture.

We deduced from that the validity of the KacemOuerfelli equations for ternary mixture in addition to pure and binary liquid mixtures only for the first Group of studied liquids mixtures. This indicates also the importance of taking into consideration the density of ternary liquid mixtures in this study.

This result is important in fluids engineering since the validation of these equations for ternary liquid mixtures simplifies the estimation of viscous behavior and the ensuing calculations by reducing the number of viscosity equation parameters and thus facilitating manipulations. We expect that this study will be useful in large domains of applied chemistry and engineering and will open new interesting field of profitable investigations such as the study of specific groups or families of organic liquids solvents. It could also pave the way to estimate more accurate values of confirm also the precedent result about the good quality of approximation. Indeed, it appears clearly that the relative deviations are very low for both parameters.

the equation's parameters, when the natures of fluids are classified separately.

\section{Disclosure statement}

No potential conflict of interest was reported by the authors.

\section{References}

1- N. Ouerfelli, M. Bouaziz, J.V. Herráez, Treatment of Herráez Equation Correlating Viscosity in Binary Liquid Mixtures exhibiting strictly monotonous distribution, Phys. Chem. Liq. 2013, 51, 55-74.

2- J.V. Herráez, R. Belda, O. Diez, M. Herráez, An Equation for the Correlation of Viscosities of Binary Mixtures, J. Solution Chem. 2008, 37, 233-248.

3- J.B. Irving, NEL Report Numbers 630 and 631, National Engineering Laboratory, East Kilbride: Glasgow, 1977.

4- S.W. Benson, Thermochemical Kinetics, 2nd ed. Wiley: New York, 1976.

5- J.A. Dean, Handbook of Organic Chemistry, McGraw-Hill: New York, 1987.

6- $\quad$ S. Glasstone, K.L. Laidler, H. Eyring, The theory of rate rocess, McGraw-Hill: New York, 1941.

7- H. Eyring, Viscosity, plasticity, and diffusion as examples of absolute reaction rates, J. Chem. Phys. 1936, 4, 283-291.

8- H. Eyring, J.O. Hirschfeldern, The theory of the liquid state, J. Phys. Chem. 1937, 41, 249-257.

9- H. Eyring and M.S. John, Significant Liquid Structure, Wiley: New York, 1969.

10- P.T. Cummings, D.J. Evans, Non-equilibrium molecular dynamics approaches to transport properties and non-Newtonian fluid, Ind. Eng. Chem. Res. 1992, 31, 1237-1252.

11- J.G. Kirkwood, F.P. Buff, M.S. Green, The statistical mechanical theory of transport processes. III. The coefficients of shear and bulk viscosity of liquids, J. Chem. Phys. 1949, 17, 988-994.

12- J. De. Guzman, Relation between fluidity and heat of fusion, Anales Soc. Espan. Fis. Quim. 1913, 11, 353-362.

13- C.R. Duhne, Viscosity-temperature correlations for liquids, Chem. Eng. 1979, 86, 83-91.

14- D.S. Viswanath, G. Natarajan, Databook on Viscosity of Liquids, Hemisphere: New York, 1989.

15- N.V.K. Dutt, D.H.L. Prasad, Representation of the Temperature Dependence of the Viscosity of Pure Liquids, Private Communication, Chemical Engineering Division, Indian Institute of Chemical Technology: Hyderabad, 2004. 
16- R.C. Reid, J.M. Prausnitz, B.E. Poling, Properties of Gases and Liquids, McGraw-Hill: New York, 4th Ed., 1987.

17- H. Vogel, Das Temperatur-abhängigkeitsgesetz der Viskosität von Flüssigkeiten, Physik Z. 1921, 22, 645-646.

18- G.S. Fulcher, Analysis of Recent Measurements of the Viscosity of Glasses, J. Am. Ceram. Soc. 1925, 8, 339-355.

19- G. Tammann, W. Hesse, Abhängigkeit der Viscosität von der Temperature bieunterkühlten Flüssigkeiten, Z. Anorg. Allg. Chem. 1926, 156, 245-251.

20- Jr. E. Goletz, D. Tassios, An Antoine type equation for liquid viscosity dependency to temperature, Chem. Proc. Des. Dev. 1977, 16, 75-79.

21- T.E. Thorpe, J.W. Rodger, Bakerian Lecture: On the Relations between the Viscosity (Internal Friction) of Liquids and Their Chemical Nature, Phil. Trans. 1895, 185, 397-710.

22- L.A. Girifalco, Temperature dependence of viscosity and its relation to vapor pressure for associated liquids, J. Chem. Phys. 1955, 23, 2446-2447.

23- D.S. Viswanath, T.K. Ghosh, G.H.L. Prasad, N.V.K. Dutt, K.Y. Rani, Viscosity of Liquids. Theory, Estimation, Experiment, and Data, Springer: Dordrecht, The Netherlands, 2007.

24- T.E. Daubert, R.P. Danner, Physical and Thermodynamic Properties of Pure Chemicals -Data Compilation Design Institute for Physical Properties Data, AIChE, Taylor and Francis: Washington DC, 1989-1994.

25- R.H. Kacem, N. Ouerfelli. J.V. Herráez, M. Guettari, H. Hamda, M. Dallel, Contribution to modeling the viscosity Arrhenius type-equation for some solvents by statistical correlation analysis, Fluid Phase Equilibr. 2014, 383, 11-20.
26- B. B. Gurung, M. N. Roy, Study of densities, viscosity deviations, and isentropic compressibilities of ternary liquid mixtures of water and ethane-1,2-diol with some monoalcohols at various temperatures, Phys. Chem. Liq. 2007, 45, 331-343.

27- A. Rodríguez, A.B. Pereiro, J. Canosa, J. Tojo, Dynamic viscosities of the ternary liquid mixtures (dimethyl carbonate + methanol + ethanol) and (dimethyl carbonate + methanol + hexane) at several temperatures, J. Chem. Thermodyn. 2006, 38, 505-519.

28- R.H. Kacem, N. Ouerfelli and J.V. Herráez, Viscosity Arrhenius Parameters Correlation: Extension from Pure to Binary Liquid Mixtures, Phys. Chem. Liq. 2015, 53, 776-784.

29- R.H. Kacem, N.O. Alzamil and N. Ouerfelli, Sensitivity of viscosity Arrhenius parameters to polarity of liquids, Russian J. Phys. Chem. A. 2017, 91, 1654-1659.

30- R.H. Kacem, N. Al-Omair, M. Alkhaldi, A.A. Al-Arfaj and N. Ouerfelli, Sensitivity of viscosity Arrhenius-type equation to density of liquids, Asian J. Chem. 2016, 28, 2407-2410.

31- A.A. Al-Arfaj, R. H. Kacem, L. Snoussi, N.Vrinceanu, M. A. Alkhaldi, N. O. Alzamel and N. Ouerfelli, Correlation Analysis of the viscosity Arrhenius-type equations parameters for some binary liquids mixtures, Mediterr. J. Chem. 2017, 6(2), 23-32.

32- Wonacott T.H.\& Wonacott R.J. Introductory Statistics, 5th edition, John Wiley, 1990.

33- F. Wilcoxon, Individual comparisons by ranking methods, Biom. Bull. 1945, 1, 80-83. 